\title{
ХИМИЧЕСКИ ИНДУЦИРОВАННЫЕ ЛЕЧЕБНЫЕ СУДОРОГИ В ПСИХИАТРИИ - ПРЕДШЕСТВЕННИКИ ЭЛЕКТРОСУДОРОЖНОЙ ТЕРАПИИ (К 80-ЛЕТИЮ ЭЛЕКТРОСУДОРОЖНОЙ ТЕРАПИИ): НАУЧНЫЙ ОБЗОР
}

\author{
Быков Ю.В., Беккер Р.А.
}

Цель исследования: Представить читателю исторический обзор о химически индуцированных (камфорных, кардиазоловых и триазоловых) лечебных судорогах, как предиественниках современной электросудорожной терапии (ЭСТ), об истории открытия этого метода, о механизмах его лечебного воздействия, сравнительной эффективности и безопасности в сопоставлении с ЭСТ, причинах забвения и отказа, и напомнить об уникальной высокой эффективности ЭСТ в лечении депрессий и кататонии, непревзойдённой до сих пор.

Методология проведения работы: Мы провели поиск исторической литературы о лечебном применении химически индуцированных судорог c использованием PubMed, Google Scholar, Science Direct u Web of Science, а также библиографических списков в статьях Википедии и монографиях, посвящённых ЭСТ. Найденные источники были нами обработаны, обобщены и представлены в настоящем обзоре.

Результаты: Полученные нами в результате составления настоящего обзора литературные данные свидетельствуют о том, что химически индуиированные судороги действительно обладали лечебным воздействием при ряде психических расстройств (в частности, депрессиях, маниакальных и смешанных состояниях, шизофрении, кататонии), обладали эффективностью и безопасностью, сопоставимой с тогдамней немодифицированной ЭСТ, и при меньшем потенциале вызывания когнитивных нарушений. Химически индуцированные лечебные судороги не только послужили предтечей для изобретения ЭСТ, но и позволили устранить существовавший до начала ХХ века терапевтический нигилизм в отношении возможностей лечения психических заболеваний, что 
создало предпосылки для дальнейтего развития исследований в этой области и для последующего зарождения психофармакотерапии. Более того, сама идея химической индукиии лечебных судорог с использованием более безопасных агентов и в модифичированной форме (с премедикацией, общей анестезией, миорелаксантами и искусственной вентиляиией лёгких) сохраняет свою привлекательность и сегодня.

Область применения результатов: результаты нашего обзора свидетельствуют о высоком терапевтическом потенциале современной модифииированной ЭСТ, как наследниць кардиазоловой судорожной терапии, в лечении тяжёльх и резистентных форм психических заболеваний, и о том, что современная модифицированная ЭСТ заслуживает гораздо более широкого применения в психиатрии.

Ключевые слова: химически индуцированные судороги; кардиазоловая судорожная терапия; электросудорожная терапия; камфора; кардиазол; триазол; история психиатрии.

\title{
CHEMICALLY INDUCED THERAPEUTIC SEIZURES AS PREDECESSORS TO THE MODERN ELECTROCONVULSIVE THERAPY (FOR THE 80th ANNIVERSARY OF ELECTROCONVULSIVE THERAPY): SCIENTIFIC REVIEW
}

\author{
Bykov Yu.V., Bekker R.A.
}

Purpose: To present the reader with thorough historical overview of chemically induced (by the use of camphor, cardiazole or triazole) seizures as predecessors of modern electroconvulsive therapy (ECT), the history of the discovery of this method, the mechanisms of its therapeutic effect, its comparative efficacy and safety in comparison with ECT, the cause of its dismissal in the favor of ECT, and remind the reader of the uniquely high effectiveness of ECT in the treatment of depression and catatonia, unsurpassed until now.

Methodology: We have performed a thorough search for historical literature on the therapeutic use of chemically induced seizures with the use of PubMed, Google Scholar, Science Direct and Web of Science, as well as bib- 
liographic lists in Wikipedia articles and monographs on ECT. The sources we found were processed, summarized and presented in this review.

Results: The literature data obtained as a result of the present review show that chemically induced seizures did indeed have a curative effect in a number of mental disorders (in particular, depression, mania and mixed states, schizophrenia, catatonia), with the efficacy and safety comparable to the unmodified ECT, together with lower potential for causing cognitive impairment. Chemically induced seizures not only served as a predecessor to the invention of ECT, but also allowed to eliminate the therapeutic nihilism that existed before the beginning of the 20th century with regard to the possibilities of treating mental illnesses, which created the prerequisites for the further development of research in this field and for the subsequent emergence of psychopharmacotherapy. Moreover, the very idea of chemical induction of therapeutic seizures with the use of safer agents and in a modified form (with premedication, general anesthesia, muscle relaxants and artificial ventilation of the lungs) retains its attractiveness even today.

Scope: The results of our review indicate the high therapeutic potential of modern modified ECT, as the modern successor of the camphor and cardiazole I triazole convulsive therapy, in the treatment of severe and resistant forms of mental illness, and that modern modified ECT deserves a much wider application in psychiatry.

Keywords: chemically induced seizures; cardiazol convulsive therapy; electroconvulsive therapy; camphor; cardiazole; triazole; history of psychiatry

\section{Введение}

Идея лечить психические расстройства с помощью искусственного вызывания у больного судорожных припадков путём введения в организм больного тех или иных химических веществ, обладающих судорожным действием (так называемых «судорожных ядов») обязана своим зарождением сочетанию двух ранее известных фактов [Kennedy A., 1940].

С одной стороны, достаточно давно было известно, что некоторые химические вещества в токсических, но не летальных дозах способны вызывать судороги у человека, но при этом не приводить к летальному исходу. Введение этих же веществ в достаточно высоких (токсических), но не летальных дозах в организм подопытных животных также способно вызывать у них контролируемые судороги без смертельного исхода и без видимого вреда для организма животного. С другой же стороны, 
также было давно отмечено, что развитие спонтанных судорог по любой причине (например, из-за высокой температуры - фебрильные судороги, или из-за спонтанно возникшей гипогликемии, черепно-мозговой травмы - ЧМТ, отравления, инсульта и т. п.) у больных, страдающих шизофренией, депрессивными или маниакальными состояниями, в некоторых случаях способствовало быстрому улучшению психического состояния и даже становлению ремиссии [Kennedy А., 1940].

Тщательный ретроспективный анализ литературы показывает, что, как и многие другие относительно недавние достижения медицинской науки, идея использования камфоры, как судорожного яда, для искусственного вызывания судорог с целью лечения психических заболеваний, на самом деле не была такой уж новой. Так, сохранились исторические сведения о том, что немецкий врач Леопольд Ауэнбруггер ещё в 1764 году пытался применять при бредовой мании смесь, содержащую камфору, для вызывания судорог. При этом маниакальное состояние и бред нередко купировались. А в 1781 году лондонский врач Уильям Оливер зафиксировал случай успешного купирования мании после судорожного припадка, вызванного введением в организм пациента большого количества камфоры [Kennedy A., 1940].

Подобные исторические предшественники обнаруживаются при тщательном ретроспективном анализе литературы не только у химической судорожной терапии, но и у пиротерапии (лечения психических заболеваний при помощи искусственного повышения температуры тела), и у электросудорожной терапии (ЭСТ). Так, ещё в I веке нашей эры римские врачи пытались лечить мигрень и депрессивные состояния прикладыванием электрических рыб (в том числе электрических скатов) к голове больного, что вызывало судороги и потерю сознания, и часто приводило к развитию терапевтического эффекта [Нельсон А.И., 2005]. Аналогично, уже давно существовали исторические наблюдения о том, что состояние психически больных нередко улучшается после перенесённого лихорадочного заболевания [McCrae N. et al, 2006; Беккер Р.А., Быков Ю.В., 2016].

Наблюдения об эффективности лихорадки в лечении психических заболеваний послужили предтечей для изобретения австрийским психиатром Юлиусом Вагнер-Яуреггом методики так называемой маляриотерапии - преднамеренного заражения психически больных трёхдневным штаммом малярийного плазмодия с целью искусственного вызывания лихорадки. После перенесения больным определённого количества лихорадочных приступов малярию купировали хинином и метиленовым си- 
ним [McCrae N. et al, 2006; Беккер Р.А., Быков Ю.В., 2016]. Такая терапия была особенно эффективной в лечении так называемого «прогрессивного паралича» (нейросифилиса). Однако она нередко оказывала положительный эффект и при других психических заболеваниях. Например, она могла оказать успокаивающее действие на возбуждённых и агрессивных больных шизофренией или маниакальными состояниями, и могла способствовать купированию бреда и галлюцинаций [Беккер Р.А., Быков Ю.В., 2016]. За изобретение этой методики Ю. Вагнер-Яурегг в 1927 году был награждён Нобелевской премией по медицине и физиологии, став, таким образом, первым психиатром, награждённым Нобелевской премией, причём именно за исследования в области психиатрии [Беккер Р.А., Быков Ю.В., 2016].

Довольно скоро было отмечено, что если для эффективного лечения больных с «прогрессивным параличом» при помощи маляриотерапии наибольшее значение имела степень выраженности лихорадки и количество перенесённых лихорадочных приступов, то у больных с шизофренией, депрессивными и маниакальными состояниями наибольший лечебный эффект отмечался именно в тех случаях, когда на фоне высокой температуры у больного возникали фебрильные судороги [Беккер Р.А., Быков Ю.В., 2016]. При этом главным образом подвергались редукции так называемые «позитивные» симптомы болезни (бред, галлюцинации, психомоторное возбуждение, агрессивность, нарушения мышления и поведения) [Беккер Р.А., Быков Ю.В., 2016].

Примерно в то же время, в начале XX века, Манфред Закель предложил свой метод лечения психических заболеваний (в основном шизофрении) при помощи вызывания сопорозного или коматозного состояния введением высоких доз инсулина, вызывающих гипогликемический сопор или гипогликемическую кому (инсулино-сопорозная терапия - ИСТ, или инсулинокоматозная терапия - ИКТ) [Быков Ю.В., 2014]. Чуть ранее Якоб Клоэзи предложил лечить психические заболевания длительным сном, вызванным введением барбитуратов, хлоралгидрата или паральдегида, нередко в смесях [Быков Ю.В., 2011]. Распространялась также методика лечения психических заболеваний с помощью кратковременного эфирного или хлорэтилового рауш-наркоза или амитал-кофеиновых растормаживаний.

Опять-таки, было подмечено, что часто (но не всегда) особенно выраженный лечебный эффект при применении этих методов лечения наблюдался в тех случаях, когда на фоне гипогликемического состояния 
возникали гипогликемические судороги, или когда на фоне выхода из наркоза или длительного сна возникали «судороги отмены» (абстинентные или посленаркозные судороги). Известный со времён Гиппократа лечебный эффект депривации сна при депрессивных состояниях тоже нередко бывал особенно выраженным в тех случаях, когда у предрасположенных больных на фоне лишения сна возникали судороги [Быков Ю.В. с соавт, 2013]. Вся эта совокупность фактов не могла не подвести к мысли о том, что лечебным фактором во многих из этих случаев, возможно, может являться не сама по себе гипогликемическая кома, повышение температуры тела, депривация сна или лечебный сон либо наркоз, а возникающие при этом или после этого судороги (хотя сегодня мы знаем, что для всех упомянутых методов этот фактор не является единственным).

\section{Зарождение химически индуцированных лечебных судорог}

В начале XX века было принято считать, что шизофрения или маниакально-депрессивный психоз (МДП) и эпилепсия биологически несовместимы, и что они либо вообще не наблюдаются, либо крайне редко наблюдаются одновременно у одного и того же пациента. Также в литературе имелись многочисленные наблюдения о том, что в тех случаях, когда у больного с шизофренией или с МДП спонтанно возникали эпилептиформные судороги по любой причине (например, фебрильные судороги на фоне лихорадочного состояния, или судороги после ЧМТ, инсульта, или при отравлениях судорожными ядами), после этого нередко наступало временное улучшение психического состояния или временное смягчение клинической симптоматики болезни, вплоть до временного выхода в ремиссию. Так, в частности, в 1930 году Макс Мюллер описал два случая больных шизофренией, у которых наступило улучшение клинического состояния после спонтанно возникших эпилептических припадков [McCrae N. et al, 2006].

На базе этих наблюдений некоторые врачи, полагая, что в крови больных эпилепсией могут содержаться какие-то вещества, обладающие антагонистическим действием по отношению к шизофрении и другим психозам, даже пытались переливать одногруппную кровь больных эпилепсией - больным шизофренией. Но эти эксперименты не дали никаких положительных результатов. Тем не менее, молодой венгерский психиатр Ласло Медуна заинтересовался как этими экспериментами с переливанием крови эпилептиков шизофреникам, так и вообще в целом проблемой 
биологической совместимости или несовместимости эпилепсии и шизофрении у одного и того же пациента. Изучение этого вопроса Л. Медуна начал с составления исчерпывающего обзора литературы о совместимости эпилепсии и шизофрении. По завершении этого обзора он, вслед за своими предшественниками, также пришёл к выводу о «биологической несовместимости» эпилепсии и шизофрении и о том, что эти два заболевания очень редко сочетаются у одного и того же больного, и что в тех случаях, когда у больного с шизофренией развивалась эпилепсия (например, после ЧМТ), это нередко приводило к ремиссии или улучшению течения шизофрении [Dhunjibhoy J.E., 1938].

Позднее в Исследовательском институте мозга в Будапеште (Венгрия) Л. Медуна занялся посмертным сравнительным гистологическим исследованием головного мозга (ГМ) больных с эпилепсией и с шизофренией, и описал различия в посмертном гистологическом строении мозгового вещества больных с эпилепсией и с шизофренией [McCrae N. et al, 2006]. По его данным, собранным на основе множества патологоанатомических вскрытий, в мозговой ткани больных эпилепсией наблюдалось усиленное разрастание, или «гиперплазия» или «гипертрофия», нейроглии (белого вещества), с частичным замещением ею нейронов (серого вещества). В то же время у больных шизофренией, по его данным, наблюдался противоположный эффект - снижение количества глиальных клеток в мозгу, то есть относительная «атрофия» или «гипоплазия» нейроглии [Fink M.,1984].

На основании вышеупомянутых данных Л. Медуна предположил, что причиной разрастания нейроглии при эпилепсии являются перенесённые больным судорожные припадки, а причиной гибели глиальных клеток при шизофрении и развития атрофии нейроглии являются перенесённые больным психозы или хронический шизофренический процесс. Из этого Л. Медуна вывел предположение о том, что искусственно вызванные эпилептические припадки, возможно, могут обратить вспять или затормозить процесс потери глиальных клеток больным с шизофренией и, таким образом, могут оказать лечебное воздействие на больных с шизофренией [Fink M.,1984]. Напомним, что к этому времени уже существовало немало данных о том, что многие так называемые «судорожные яды» в правильно подобранных (токсических, но не летальных) дозах могут вызывать судороги, как у людей, так и у экспериментальных животных, но не приводить при этом к летальному исходу [Fink M.,1984].

Уже в 1934 году, после длительного тестирования в экспериментах на животных различных судорожных ядов, Л. Медуна остановил свой выбор 
потенциального терапевтического агента для вызывания искусственных (химически индуцированных) судорог на камфоре. Камфора - это смола природного происхождения, обладающая свойствами дыхательного и сердечно-сосудистого аналептика, а также способностью стимулировать ЦНС и оказывать общетонизирующее, пробуждающее действие. Подобно многим другим дыхательным аналептикам и психостимуляторам, при передозировке камфора способна вызывать эпилептиформные судороги. К важным преимуществам камфоры перед другими доступными в то время судорожными ядами, такими, как стрихнин, пикротоксин, препараты дигиталиса (наперстянки), кофеин, теофиллин, относилась меньшая токсичность, более лёгкое вызывание судорог, бОльшая предсказуемость и управляемость судорог, меньшая летальность после введения судорожной дозы [Fink M.,1984].

После успешного испытания камфоры на морских свинках, у которых после введения заведомо токсической (судорожной), но не смертельной дозы камфоры удавалось надёжно и предсказуемо вызывать длительные генерализованные тонико-клонические припадки без летального исхода, Л. Медуна решил попробовать ввести камфору первым шести своим пациентам, страдающим шизофренией. Позднее сам Л. Медуна в своей автобиографии подробно описал первый официальный сеанс камфорной судорожной терапии. Это случилось 23 января 1934 года в 16:00 в Венгерском королевском национальном институте психиатрии и неврологии в Будапеште. Шести пациентам с кататонической формой шизофрении был внутримышечно введён 20\% масляный раствор камфоры [McCrae N. et al, 2006; Baran B. et al, 2008; Gazdag G. et al, 2009; Быков Ю.В., Беккер Р.А., 2016]. При этом ни у одного из шести пациентов после первого введения камфоры не произошло ожидаемого судорожного припадка (сегодня мы знаем, что первоначально рассчитанная Л. Медуной, исходя из экспериментов на морских свинках, судорожная доза камфоры оказалась слишком мала для человека, так как простой пересчёт на массу тела не учитывал видоспецифические отличия метаболизма камфоры и величины судорожного порога). Однако Л. Медуна не разочаровался в самой идее камфорной судорожной терапии, а попробовал увеличить всем больным дозу камфоры вдвое на следующий день. Это привело к успешному вызыванию судорожных припадков у всех шести больных и к развитию у них терапевтического эффекта [Gazdag G. et al, 2009].

Особенно явная положительная динамика после лечения камфорной судорожной терапией была описана у 33-летнего больного с кататони- 
ческой формой шизофрении, который до этого находился в больнице без какого-либо улучшения уже в течение 4 лет. Как описывал позднее сам Л. Медуна, после пяти сеансов вызванных камфорой лечебных судорог у больного наступило драматическое улучшение: «...утром 10 февраля 1934 года (через два дня после пятой инъекции), впервые за четыре года, он встал с постели, начал говорить, попросил завтрак, оделся сам без всякой помощи, проявлял выраженный интерес к окружающему и спросил, как долго он находится в больнице? Когда мы сказали ему, что он находится на лечении 4 года, он не поверил нам...» [Fink M.,1984; Whitaker R., 2002].

Вскоре после этого Л. Медуна поделился своими наблюдениями с другими врачами, рассказывая о «возрождённой жизни психически больного», и сравнивая это с тем, как это происходило у М. Закеля при проведении первых сеансов ИКТ и у Я. Клоэзи на начальном этапе внедрения продлённого сна в лечении шизофрении (как М. Закель, так и Я. Клоэзи были просто поражены положительными результатами при открытии своих методов лечения).

Пять других пациентов с кататонической формой шизофрении, которых Л. Медуна продолжил лечить вызыванием судорог при помощи камфоры, также вскоре получили положительный эффект от лечения. Это породило у Л. Медуны большой оптимизм и надежду на новый метод лечения [Whitaker R., 2002]. Воодушевившись этими первыми результатами, Л. Медуна продолжил свои эксперименты с медикаментозным вызыванием судорог при помощи внутримышечного введения больших доз 20\% масляного раствора камфоры с интервалом 2-3 дня. Постепенно он увеличивал количество пациентов, подвергавшихся этому новому виду терапии. Первые эксперименты Л. Медуны показали, что при помощи внутримышечного введения больших доз 20\% масляного раствора камфоры судорожные припадки удаётся вызывать более чем у половины больных. При этом Л. Медуной были описаны судороги разной продолжительности (в том числе и полное отсутствие судорог), а также сдвоенные, многократные (повторные) и отсроченные (поздние) судороги, а также психомоторные эквиваленты судорожных припадков (эпилептическое возбуждение или эпилептические психозы, эпизоды сумеречного помрачения сознания) после введения больших доз камфоры [Быков Ю.В., Беккер Р.А., 2016].

Позднее, уже в 1935 году, Л. Медуна опубликовал первые результаты применения камфорной судорожной терапии у 26 пациентов с шизофренией. По его данным, 10 из 26 больных значительно улучшились 
в краткосрочной перспективе, у 3 больных улучшения были незначительными, а у остальных 13 их не было совсем. Особенно выраженный эффект от камфорной судорожной терапии наблюдался у больных с кататонической формой шизофрении или с острыми аффективно-бредовыми приступами. Меньший эффект наблюдался у пациентов с острыми галлюцинаторно-бредовыми приступами без выраженной аффективной или кататонической симптоматики, и ещё меньший - у больных с хроническими галлюцинаторно-бредовыми состояниями без кататонии или выраженной аффективной симптоматики [Meduna L., 1935; Baran B. et al, 2012].

Настойчивость Л. Медуны в продолжении своих экспериментов и в продвижении своего нового метода лечения была тем более поразительна и примечательна, что его учитель и наставник Кароль Шаффер, считавшийся в 30-х годах XX века в Венгрии ведущим авторитетом в области нейропсихиатрии, принадлежал к распространённой в то время когорте терапевтических нигилистов, полагавших, что шизофренический процесс по определению неизлечим и неостановим, и всегда имеет неуклонно прогрессирующее течение с исходом в глубокий дефект и распад личности («dementia praecoх» по Эмилю Крепелину), и что любые активные терапевтические вмешательства при шизофрении не только бесполезны, но и наносят вред мозгу. Кроме того, К. Шаффер полагал, что рассуждения Л. Медуны об «обращении вспять процесса потери нейроглии при шизофрении при помощи вызывания терапевтических судорожных припадков», послужившие теоретической основой для предложенного Л. Медуной судорожного метода лечения, чрезвычайно неправдоподобны, а сам метод опасен и вреден [Meduna L.J., 1954].

К. Шаффер в то время был далеко не единственным таким скептиком и терапевтическим нигилистом. Из-за такой позиции ведущих психиатров, а также из-за объективных сложностей в применении методики камфорной судорожной терапии, эта методика столкнулась с большими трудностями при внедрении в психиатрические больницы других стран Центральной Европы. Единственным исключением была Швейцария, где терапевтический нигилизм был менее популярен, и где до этого уже была успешно разработана и внедрена в терапевтическую практику Я. Клоэзи методика лечения длительным сном [McCrae N. et al, 2006].

Сам же Л. Медуна полагал, что эпилептические припадки могут играть при психозах, в том числе при шизофрении, некую «защитную» или «очищающую» (дезинтоксикационную) роль, приводя к «сжиганию» или выведению из мозга и организма неких гипотетических, пока неиз- 
вестных, токсинов во время припадка [Fink M., 2004]. Он обосновывал наблюдаемый терапевтический эффект химически индуцированных судорог при помощи двух основных гипотез. Первой гипотезой была его вера в существование биологического антагонизма между шизофренией и эпилепсией. Эту веру он обосновывал как клиническими и эпидемиологическими, так и патологоанатомическими (нейропатологическими) данными [Meduna L.J., 1935;1937;1954]. Вторая его гипотеза состояла в утверждении о том, что все наблюдаемые в клинической практике случаи шизофрении можно разделить на три основных типа в соответствии с их этиологией и патогенезом: эндогенные, или «генотипические», экзогенные, или «паратипические», и вызванные комбинацией эндогенных и экзогенных (генетических и не-генетических) факторов [Meduna L.J., 1935]. При этом Л. Медуна предполагал, что химически индуцированные судорожные припадки будут эффективны только для двух последних «не генетических» или «не полностью генетических» типов шизофрении, в этиологии и патогенезе которых играют роль, наряду с эндогенными или генетическими факторами, также экзогенные или не-генетические факторы. Нередкое отсутствие эффекта от судорожной терапии при хронических галлюцинаторно-параноидных формах шизофрении, в противоположность кататоническим или острым аффективно-бредовым формам, Л. Медуна объяснял как раз сугубо «эндогенной», или генетической, природой этих форм шизофрении [Gazdag G. et al, 2009].

\section{От камфоры к кардиазолу (метразолу)}

Применение камфоры для вызывания лечебных судорог сталкивалось с рядом проблем. Прежде всего, камфора нерастворима в воде. Это вынуждало использовать её в масляном растворе и вводить только внутримышечно. Из-за медленного и не всегда надёжного всасывания масляного раствора камфоры при его внутримышечном введении, судороги после введения камфоры возникали далеко не всегда. Даже в тех случаях, когда они возникали, то их возникновение часто бывало отсроченным и непредсказуемым по времени (через несколько часов или даже на следующий день после инъекции). От момента начала действия камфоры до момента успешного вызывания судорог или момента окончания её действия больные нередко испытывали сильнейшее психомоторное возбуждение, страх, тревогу, бессонницу, неоднократные панические атаки. Это мешало, в случае недостаточности дозы и неуспешности вызывания судорог, своевременно добавить дозу камфоры (сделать повторную инъекцию), 
так как возбуждённые и агрессивные больные нередко просто не давались сделать повторную инъекцию [Meduna L., 1935; McCrae N. et al, 2006; Gazdag G. et al, 2009; Mankad M.V. et al, 2010; Cooper K., Fink M., 2014].

Кроме того, из-за трудностей дозирования камфоры и предсказания её судорожной дозы для конкретного больного в конкретном сеансе, а также из-за её медленного всасывания и медленного выведения и склонности к кумуляции судороги, в тех случаях, когда они возникали, часто бывали слишком длительными, повторными или неоднократными. Это часто приводило к развитию осложнений, таких, как мышечно-скелетные травмы (растяжения мышц и связок, переломы, вывихи), длительное апноэ и др. Инъекции масляного раствора камфоры были очень болезненными и часто приводили к развитию олеом (масляных инфильтратов) и даже абсцессов мягких тканей [Meduna L., 1935; McCrae N. et al, 2006; Gazdag G. et al, 2009; Mankad M.V. et al, 2010; Cooper K., Fink M., 2014].

Из-за всех этих неблагоприятных факторов Л. Медуна решил в дальнейшем попытаться использовать для вызывания лечебных судорог не камфору, а другой аналептический агент - пентаметилентетразол, или кардиазол (в США он назывался Метразол, а в СССР - коразол). Кардиазол представляет собой сердечно-сосудистый и дыхательный стимулятор (аналептик), а в больших дозах - судорожный яд. Химически он является осколком молекулы камфоры (ее аналептически активной частью). В отличие от камфоры, он водорастворим и имеет быстрое, короткое и более предсказуемое и надёжное действие, и пригоден для введения в вену [Meduna L., 1935; McCrae N. et al, 2006; Gazdag G. et al, 2009; Mankad M.V. et al, 2010; Cooper K., Fink M., 2014]. Как показали первые эксперименты Л. Медуны с кардиазолом, проведённые им ещё в 1937 году, при быстром (толчкообразном) введении в вену большой дозы кардиазол вызывает судорожные припадки надёжно и быстро (как правило, в течение первых 30 секунд после введения, максимум - в течение первых нескольких минут после введения). Кроме того, кардиазол не только был гораздо удобнее для применения, чем камфора, но и дешевле, что было немаловажно в условиях ограниченности ресурсов и недостаточного финансирования психиатрических больниц [Meduna L., 1937].

После перехода Л. Медуны с камфоры на кардиазол в качестве терапевтического агента для вызывания лечебных судорог, успешность его метода резко возросла. Так, из первых 110 пролеченных Л. Медуной при помощи кардиазола больных шизофренией положительный терапевтический эффект (полное купирование или значительное смягчение сим- 
птоматики) наблюдался более чем у половины. Как и ранее, в случаях с камфорой, особенно разительным эффект кардиазоловой судорожной терапии был при кататонических или аффективно-бредовых формах шизофрении. Некоторые из пролеченных Л. Медуной при помощи кардиазоловой судорожной терапии больных до этого не имели ни малейшего улучшения в течение более 10 лет наблюдения и лечения. Вскоре методика кардиазоловой (коразоловой в СССР, метразоловой в США и Европе) судорожной терапии начала быстро распространяться по многим европейским и американским клиникам. Широко применялась она и в СССР [Whitaker R., 2002].

Метразоловая судорожная терапия быстро стала одним из основных терапевтических агентов в американской психиатрии, наряду с ИКТ. Приводятся данные о том, что уже к 1939 году 70 процентов психиатрических больниц США использовали метразоловую судорожную терапию в качестве основного или одного из основных методов лечения. С 1936 по 1941 годы в США этому виду лечения подверглись почти 37000 психически больных, в основном с шизофренией, преимущественно с кататоническими её формами [Whitaker R., 2002]. Тем не менее, кардиазоловая судорожная терапия также имела недостатки и побочные эффекты, хотя и была гораздо удобнее, чем использование в этих целях камфоры.

К недостаткам кардиазоловой судорожной терапии относились, в частности, возникновение сильного страха, тревоги и возбуждения или даже панических атак от момента введения кардиазола до момента потери сознания и возникновения собственно судорог (хотя этот период длился не так долго, как в случае камфоры, но достаточно, чтобы больные сильно боялись этого вида терапии), длительное апноэ, мышечно-скелетные травмы (растяжения мышц и связок, вывихи и переломы, включая переломы позвонков со всеми вытекающими последствиями в виде нарушения функций спинного мозга и инвалидизации больного) [McCrae N., 2006]. Кроме того, судороги после введения кардиазола, как и в случае с камфорой, возникали не всегда, а возникающие после его введения возбуждение, страх и тревога нередко мешали сразу же повторить инъекцию. В тех же случаях, когда они возникали, они нередко оказывались слишком длительными, отсроченными или повторными (многократными). Это повышало риск осложнений, в частности мышечно-скелетных травм или длительного апноэ. Эта проблема в случае с кардиазолом возникала гораздо реже, чем в случае применения камфоры, но полностью исключена не была [McCrae N., 2006]. 


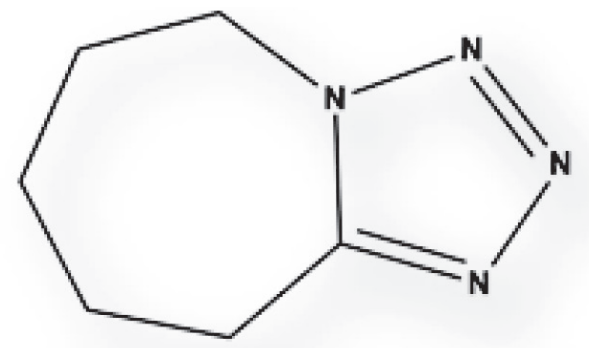

\section{CARDIAZOL (METROZOL)} Pentametilen-tetrazol 6,7,8,9-Tetrahidro-5H-tetrazol[1,5a]azepina

Рис. 1. Химическая формула кардиазола (метразола)

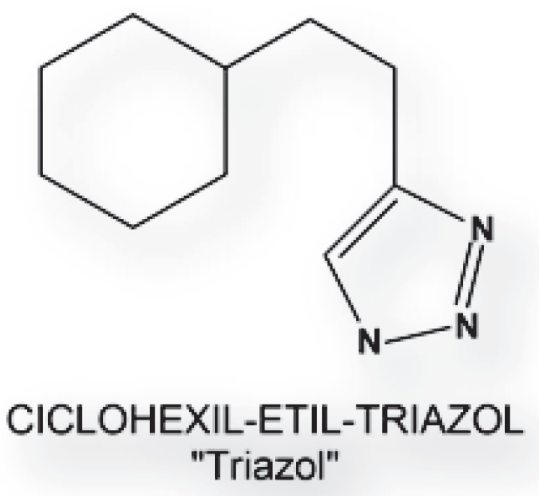

Рис. 2. Химическая формула триазола

В качестве альтернативного кардиазолу терапевтического агента для вызывания лечебных судорог был предложен также другой аналептик сходного строения - циклогексилэтилтриазол, зарегистрированный под названием Триазол. Изготовителем Триазола была немецкая лаборатория «Boehringer». Первое использование этого вещества в целях индукции лечебных судорог произошло в больнице Кейн Хилл в 1938 году в ходе эксперимента, проведённого Вилли Майер-Гроссом и Александром Уолком. В период между 
1937 и 1939 годами количество публикаций, посвящённых кардиазоловой или триазоловой судорожной терапии, резко возросло. Так, только в авторитетном британском медицинском журнале «The Lancet» в период между 1937 и 1939 годами было опубликовано 11 статей, посвящённых кардиазоловой или триазоловой судорожной терапии [McCrae N., 2006].

\section{Техника проведения}

\section{химически индуцированных лечебных судорог}

Описание процедуры вызывания лечебных судорог кардиазолом или триазолом, по сегодняшним меркам, выглядит достаточно устрашающим и негуманным. Вот как описывали методику кардиазоловых лечебных судорог авторы первой половины XX века. Толстая (большого диаметра, чтобы позволять быстрое, толчкообразное введение лекарства) инъекционная игла, соединённая со шприцем, содержащим водный раствор кардиазола, вводилась примерно на 2 сантиметра в достаточно крупную (большого диаметра) вену. При этом было необходимо тщательно следить за положением иглы в вене, чтобы избежать экстравазации, так как попадание водного раствора кардиазола в окружающие мягкие ткани могло привести к некрозу тканей. Убедившись в правильности положения иглы в вене, врач быстро (толчком) вводил раствор кардиазола в вену больного. После непродолжительного периода ожидания (обычно около 30 секунд, но бывало до нескольких минут) у больного возникала сильная тревога, паника или страх, одышка, сердцебиение, затем кашель или крик, а затем потеря сознания и генерализованный тонико-клонический судорожный припадок [Kennedy A., 1940]. При этом обычно преобладала тоническая фаза судорог. Судороги после введения кардиазола обычно длились от 30 до 80 секунд и иногда бывали отсроченными, повторными или многократными [Meduna L.J. 1937; 38].

Так же, как и при ранних (немодифицированных) вариантах ЭСТ, больному подвязывали нижнюю челюсть или завязывали рот, вставляли капу между зубами, чтобы избежать вывиха нижней челюсти, прикуса языка или губы, щек или травмы зубов во время припадка. Недержание мочи и/ или кала, а также мышечно-скелетные травмы (растяжения мышц и связок, вывихи и переломы, в том числе переломы позвонков с последующим выпадением спинальных функций) или длительное апноэ после припадка были достаточно частыми проблемами при кардиазоловой судорожной терапии. После окончания кардиазоловых судорог пациент обычно глубоко засыпал, так же, как это обычно происходит после спонтанно возникших генерализованных больших судорожных припадков [Cook L.C., 1938]. 
Оптимальная доза кардиазола или триазола чаще всего подбиралась «на глаз», методом проб и ошибок. Существовало огромное количество незначительных вариаций методики. Тем не менее, метод кардиазоловой судорожной терапии, который использовался в большинстве центров, не отличался или мало отличался от оригинальной методики, предложенной Л. Медуной. Большинство практиков использовали для вызывания судорог 10\% раствор кардиазола (метразола или коразола) [Cook L.C., 1938].

Одна из трудностей, с которыми сталкивались все практики, применявшие кардиазоловую судорожную терапию, заключалась в том, что у больных, получавших ранее такую терапию, обычно были очень плохие периферические вены. Вследствие местного раздражающего действия кардиазола на стенки вен, а также вследствие необходимости вводить кардиазол очень быстро, толчкообразно, под большим давлением (иначе судороги не развивались), у больных, подвергавшихся такой терапии, часто развивались флебиты и тромбозы и даже склерозирование периферических вен [Kennedy A., 1940]. Между тем, кардиазоловую судорожную терапию необходимо было проводить курсами (так же, как и ИКТ, а впоследствии ЭСТ), для того, чтобы добиться желаемого стойкого и длительного эффекта. Кроме того, как считалось тогда, сеансов кардиазоловой судорожной терапии нужно было больше, чем сегодня считается необходимым при применении современной модифицированной ЭСТ. Полный курс кардиазоловой судорожной терапии включал 20-30-40 и даже большее количество сеансов (сравним это с обычно рекомендуемыми сегодня для острого курса ЭСТ 6-12, но, как правило, не более 20-25 сеансов). Сеансы кардиазоловой судорожной терапии обычно проводились 2-3 раза в неделю, подобно тому, как обычно сегодня применяется ЭСТ [Whitaker R., 2002].

\section{Основные гипотезы терапевтического эффекта}

В начале применения методики химически индуцированных лечебных судорог механизмы, лежащие в основе их терапевтического эффекта, ещё не были понятны. Не до конца понятен механизм лечебного воздействия ЭСТ и сегодня. Тем не менее, уже к началу 1940-х годов существовали три основных гипотезы, пытавшиеся объяснить лечебное воздействие кардиазоловых судорог. Психоаналитическая гипотеза придавала большое значение психологическим факторам, и считала важным, если не основным, фактором в лечебном эффекте кардиазоловых или камфорных судорог возникавшие после введения кардиазола или камфоры сильный страх (в том числе страх смерти), тревогу или панику. По мысли привер- 
женцев этой теории, испытываемые больным перед возникновением судорог сильный страх и тревога, страх смерти, могут иметь некое «очистительное» значение, по типу личностного катарсиса, и могут заставить больного переосмыслить свою жизнь и своё поведение. Другая, нейроэндокринная (нейрогуморальная) гипотеза, придавала большое значение в механизмах лечебного эффекта кардиазоловых судорог происходящим при них нейроэндокринным изменениям, в частности, активации симпатической нервной системы, выбросу катехоламинов, АКТГ и кортизола, пролактина и других гормонов и гуморальных факторов. Третья гипотеза предполагала непосредственное лечебное воздействие кардиазоловых судорог на ЦНС, например, в виде гипотетического «сжигания» неких токсических веществ во время судорожного припадка (тем более что тогда уже было известно, что после спонтанных или химически индуцированных судорог в ЦНС снижаются уровни аммиака и мочевой кислоты) или в виде гипотетического «нейротрофического» действия, например, препятствования процессу атрофии нейроглии при шизофрении [Kennedy A., 1940].

Сам же Л. Медуна считал, что химически индуцированные (камфорой, кардиазолом или триазолом) судороги воздействуют на организм больного на эндокринологическом или нейроэндокринном уровне, восстанавливая «психическую гармонию» [Meduna L.J., 1943]. Уже в первых исследовательских работах по кардиазоловой судорожной терапии были установлены некоторые факты, которые и сегодня влияют на наше понимание механизмов лечебного действия ЭСТ. Так, в частности, было обнаружено, что уровни в крови таких электролитов, как калий и кальций, после судорожных припадков, вызванных введением кардиазола, почти не изменяются. Однако тогда же было установлено, что во время припадка происходит повышение уровня глюкозы в крови, которое автор связал с повышением выброса адреналина мозговой тканью надпочечников, а кортизола - их корковым слоем [Redlich F.C., 1939]. Кроме того, было показано, что содержание натрия и хлора в плазме крови также слегка увеличивается, что автор также связал с развивающейся во время припадка гиперкортизолемией. Также этим автором было показано, что стимуляторы ЦНС, такие, как диоксид углерода (углекислый газ, $\mathrm{CO}_{2}$ ) или эфедрин, снижают судорожный порог и уменьшают необходимую минимальную судорожную дозу кардиазола. Адреналин или питуитрин (вазопрессин) оказались менее эффективны в этом отношении. Стрихнин, пикротоксин, кофеин и теофиллин, по данным автора, не оказывали влияния на минимальную судорожную дозу кардиазола (хотя мы сегодня знаем, что они уменьшают судорожный порог и минимальную дозу 
тока при ЭСТ, но, по-видимому, их влияние на судорожный порог различно для разных методов вызывания судорог) [Redlich F.C., 1939].

\section{Основные терапевтические показания}

Исторически первыми показаниями к применению химической судорожной терапии с использованием сначала камфоры, а позднее кардиазола или триазола, были различные формы шизофрении, в первую очередь кататонические и острые аффективно-бредовые, в меньшей степени - острые галлюцинаторно-бредовые формы без выраженной кататонической или аффективной симптоматики, и в самую последнюю очередь - хронические галлюцинаторно-бредовые формы. Однако по мере накопления клинического опыта применения химической судорожной терапии с использованием разных агентов, будь то камфора, кардиазол или триазол, и сам Л. Медуна, и другие клиницисты, применявшие этот метод лечения, постепенно пришли к выводу, что химическая судорожная терапия, независимо от применяемого для вызывания судорог химического агента, не лечит саму шизофрению, а только способствует ускоренному становлению ремиссии в острых случаях, особенно при наличии выраженной аффективной или кататонической симптоматики. Так, в частности, уже к началу 1940-х годов было показано, что у пациентов с шизофренией с продолжительностью психоза менее 3 лет значительное клиническое улучшение или ремиссия при применении кардиазоловой судорожной терапии достигается более чем в $43 \%$ случаев, и особенно часто - при наличии выраженной аффективной или кататонической симптоматики, а также при недавно возникшем (дни, недели или месяцы) и остро протекающем психозе. В то же время у пациентов с большей длительностью и хроническим течением психоза, или с большей давностью заболевания (более 3 лет) положительный лечебный эффект от применения кардиазоловых судорог достигался только в 13,2\% случаев, преимущественно в случаях хронической кататонии [Read C.F., 1940].

По мере накопления этих наблюдений стало ясно, что основным показанием к применению химической судорожной терапии (как и к применению ЭСТ впоследствии) является не шизофрения, при которой положительные результаты лечения были кратковременными и достигались не всегда (и особенно редко они достигались в случаях хронической шизофрении без выраженной аффективной или кататонической симптоматики), а как раз именно аффективные расстройства (маниакальные, депрессивные или смешанные состояния) и кататонические состояния различного генеза [Bennett A.Е., 1939]. В начале 1940-х годов примене- 
ние ЭСТ при аффективных расстройствах (депрессивных, маниакальных и смешанных) и при шизофрении, особенно при её кататонических формах, нередко сочетали с применением кардиазоловой судорожной терапии у одного и того же больного (в тот же день или в разные дни), или же пытались использовать небольшие (сами по себе не вызывающие судорог) дозы кардиазола для снижения судорожного порога и облегчения вызывания судорожного припадка при ЭСТ [Kennedy А., 1940].

Со временем ЭСТ постепенно вытеснила кардиазоловую и триазоловую судорожную терапию. Уже к концу 1940-х годов кардиазоловая или триазоловая судорожная терапия рассматривалась в качестве метода второго, менее желательного, выбора по сравнению с ЭСТ при лечении шизофрении и аффективных расстройств, и применялась в основном при неэффективности или недостаточной эффективности ЭСТ. Напротив, ЭСТ к этому времени уже рассматривалась как метод первого, наиболее желательного, выбора и для лечения шизофрении, и для лечения аффективных расстройств. Тем не менее, достаточно благоприятные результаты от применения кардиазоловой судорожной терапии были получены при биполярном аффективном расстройстве (БАР), который в то время назывался маниакально-депрессивным психозом, МДП (причём положительный эффект наблюдался как при маниакальных, так и при депрессивных и смешанных состояниях), при депрессиях позднего возраста (называвшихся в то время «инволюционной меланхолией»), при кататонических формах шизофрении, а также в некоторых случаях тяжёлой истерии. Важно отметить, что нередко эффект от кардиазоловой судорожной терапии наблюдался и в случаях неэффективности или недостаточной эффективности ЭСТ (вероятно, вследствие в среднем большей продолжительности кардиазоловых судорог по сравнению с судорогами в ходе обычного сеанса ЭСТ, а также вследствие нередкого возникновения повторных или многократных отсроченных судорог при применении кардиазола, и вследствие того, что для кардиазоловой судорожной терапии обычно рекомендовалось гораздо большее количество сеансов, чем для ЭСТ) [Kennedy А., 1940].

Именно это (возможная эффективность кардиазоловых судорог при неэффективности ЭСТ) и позволяло в то время, в 1940-х и 1950-х годах, рассматривать метод кардиазоловой судорожной терапии в качестве метода второго выбора или альтернативы ЭСТ при её неэффективности, а не в качестве устаревшего метода, от которого следует полностью отказаться в пользу ЭСТ. Другими важными показаниями к применению кардиазоловой судорожной терапии в середине XX века (как и к приме- 
нению ЭСТ сегодня) были тяжёлый депрессивный ступор или наоборот выраженная ажитация, отказ от пищи и/или воды, быстрое ухудшение соматического состояния, выраженная суицидальная активность или высокая суицидальная опасность больного [Kennedy A., 1940].

\section{Осложнения}

Как мы уже упоминали, внутримышечные инъекции масляного раствора камфоры были очень болезненны, и часто вызывали образование масляных инфильтратов (олеом) и даже абсцессов мягких тканей. Внутривенные инъекции кардиазола также были болезненными, и часто вызывали флебиты и тромбозы и даже склерозирование периферических вен, а при случайной экстравазации вызывали некрозы окружающих мягких тканей. Кроме того, длительность периода ожидания от момента инъекции камфоры до момента развития судорожного припадка варьировалась от 30 минут до нескольких часов, а порой и до суток, а от момента инъекции кардиазола до развития припадка - от 30 секунд до нескольких минут, а порой и десятков минут. В течение этого периода ожидания припадка больные испытывали сильнейшее психомоторное возбуждение, сильнейший неизъяснимый страх и тревогу, одышку или ощущение нехватки воздуха, страх смерти или потери сознания, головокружение, тахикардию, неоднократные панические атаки [Gazdag G. et al, 2009]. Также часто наблюдались сильные головные боли, тошнота и рвота. После припадков часто отмечались мышечно-скелетные травмы (растяжения и разрывы мышц и связок, переломы и вывихи), длительное апноэ [Hayman M., Brody M.W., 1939]. Припадки часто бывали чрезмерно длительными или повторными и даже многократными.

Ретроспективный клинический анализ, проведённый в 1940 году С. Ридом на 320 пациентах с шизофренией, получавших кардиазоловую судорожную терапию, показал, что наиболее частыми из тяжёлых осложнений кардиазоловой судорожной терапии были переломы позвонков, приводящие к нарушениям функций спинного мозга и к инвалидизации больного (20-30\% случаев). Лёгочный туберкулёз активировался у 25 из 320 пациентов, вероятно, вследствие снижения иммунитета или вследствие нарушения оксигенации лёгких при припадках. Реже отмечался сепсис (бактериемия) вследствие многократных внутривенных инъекций недостаточно стерильными иглами. Поражения миокарда и развитие склонности к гипертонии наблюдались у относительно небольшого числа пациентов. Нарушения памяти и когнитивных функций при проведении кардиазоло- 
вой судорожной терапии, по данным С. Рида, отмечались реже, чем при применении ЭСТ, и были минимально выраженными [Read C.F., 1940].

Данные о высокой частоте мышечно-скелетных травм, особенно переломов позвонков, при применении кардиазоловой судорожной терапии подтверждались и другими исследователями. Так, в 1939 году психиатрический институт штата Нью-Йорк обнаружил, что переломы позвоночника у госпитализированных психиатрических пациентов, получавших кардиазол, развивались в 43\% случаев [Whitaker R., 2002].

Другим известным с первых дней применения химической судорожной терапии отрицательным побочным эффектом этого вида лечения было развитие когнитивных нарушений, в частности, более или менее продолжительной ретроградной, антероградной и фиксационной амнезии. Однако, по данным литературы, когнитивные нарушения при применении кардиазоловой или триазоловой судорожной терапии отмечались реже и были менее выраженными, чем при применении тогдашней ЭСТ. Что же касается статистики летальности, то известно, что сам Л. Медуна, лично пролечивший кардиазолом (метразолом) более 400 пациентов, не зафиксировал ни одного летального исхода. Кардиазоловая или триазоловая судорожная терапия считалась более безопасной и связанной с меньшим потенциальным летальным риском (10 летальных исходов на 3531 пролеченного пациента, или $0,28 \%$ ), чем тогдашняя ИКТ, имевшая, по данным 1940 года, смертность около 1,3\% [Whitaker R., 2002].

\section{Различные модификации}

Некоторые психиатры, в надежде добиться лучшего терапевтического эффекта, пытались сочетать у одного и того же пациента применение химически индуцированных (кардиазоловых или триазоловых) судорог и ИКТ, иногда совмещая оба метода в один день и даже в одном сеансе. Эта методика вызвала большой интерес на состоявшемся в 1937 году «Международном конгрессе по кардиазолу, инсулиновой коме и лечению глубоким сном» [McCrae N. et al, 2006]. Позднее некоторые психиатры аналогичным образом пытались сочетать у одного и того же больного химическую (кардиазоловую или триазоловую) судорожную терапию и ЭСТ, иногда в виде последовательных курсов, иногда в виде чередования или даже в один и тот же день [McCrae N. et al, 2006].

Ещё в самом начале внедрения в клиническую практику камфорной, а затем кардиазоловой и триазоловой судорожной терапии было отмечено, что перед началом судорог практически все больные успевают испытать 
сильнейшее психомоторное возбуждение, сильнейший страх, тревогу, панические атаки, одышку, тахикардию, тошноту или головную боль, страх смерти или потери сознания. Этот эффект не являлся психологически обусловленным страхом перед потерей сознания и припадком, и был непосредственно связан с биохимическим возбуждающим действием камфоры, кардиазола или триазола на ЦНС пациента, поскольку он наблюдался с самого первого сеанса, когда больному ещё не было и не могло быть известно ни о сущности терапии, ни о вызываемых ею ощущениях [Fabing H.D., 1942; Беккер Р.А., Быков Ю.В., 2016].

Эти сильнейшие субъективно неприятные и пугающие ощущения, почти всегда возникавшие перед началом судорог, приводили к тому, что в последующем больные начинали сильно бояться сеансов судорожной терапии (особенно с применением камфоры, для которой период ожидания судорог был более длительным, чем для кардиазола), плакали, умоляли не подвергать их этому виду лечения, прятались от персонала, который должен был их вести на сеанс, под кроватями или в шкафах, проявляли агрессию к персоналу, категорически отказывались от лечения, а иногда даже совершали самоубийства, только чтобы их не подвергали этому виду лечения [Fabing H.D., 1942; Беккер Р.А., Быков Ю.В., 2016].

Пациенты описывали возникавшие при этом виде лечения ощущения по-разному, сравнивая их с «поражением электрическим током», «ударом по голове», «удушьем» или «чувством надвигающейся и неотвратимой смерти, беды, катастрофы». Это побудило одного исследователя в 1942 году попытаться применить химическую судорожную терапию на фоне предварительного введения барбитурового анестетика для общего наркоза (тиопентала), чтобы исключить или уменьшить эти неприятные ощущения или вызвать их амнезию (чтобы больной не помнил их). К сожалению, это оказалось весьма сложным делом, так как кардиазол является физиологическим антагонистом барбитуратов и наоборот, и на фоне барбитуровой анестезии приходилось значительно повышать дозу кардиазола. При этом судороги нередко либо не развивались (при недостаточной дозе кардиазола), либо же пациент успевал пробудиться от наркоза до развития судорог, и, таким образом, всё равно успевал испытать до развития судорог сильнейший страх, тревогу и панику [Fabing H.D., 1942; Беккер Р.А., Быков Ю.В., 2016].

Этот же автор в том же 1942 году попытался, для исключения или уменьшения мышечно-скелетных травм, модифицировать кардиазоловую судорожную терапию (по аналогии с тем, как это делалось при первых попытках модификации ЭСТ) при помощи применения первого из доступных миоре- 
лаксантов (тубокурарина из кураре) [Fabing H.D., 1942]. Как мы уже описывали выше, при немодифицированной методике кардиазоловой судорожной терапии, так же как и при немодифицированной ЭСТ, во время судорог возникало сильное напряжение мышц. Это приводило к частому развитию мышечно-скелетных травм (растяжений и разрывов мышц, сухожилий и связок, вывихов и переломов, и особенно опасных переломов позвонков).

Особую актуальность проблеме мышечно-суставного травматизма психически больных при применении немодифицированных методик судорожной терапии придаёт то, что, как мы знаем сегодня, из-за гиперкортизолемии, гиперпролактинемии и повышенного уровня воспалительных цитокинов в крови при таких психических заболеваниях, как депрессия или шизофрения, повышен риск развития остеопороза и риск спонтанных переломов, даже в отсутствие судорожной терапии. Кроме того, многие психически больные и сегодня имеют явный или скрытый дефицит витамина $\mathrm{D}$, кальция, магния, стронция, фосфора и фтора, необходимых для нормальной минерализации костей скелета и зубов. Это связано с такими факторами, как недостаточное воздействие солнечного света вследствие длительного пребывания в стационаре, недостаточная физическая активность, плохое питание. В то время, в связи с длительным пребыванием психически больных в закрытых отделениях стационаров из-за отсутствия эффективных методов лечения психических заболеваний, а также в связи с плохими условиями их содержания и питания, значимость этого фактора и распространённость среди них остеопороза, безусловно, была ещё выше, чем сейчас.

К началу 1940-х годов в медицине начали применять исторически первый миорелаксант (тубокурарин, действующий алкалоид кураре, нервно-паралитический яд из растения, используемого некоторыми амазонскими племенами). В частности, в небольших дозах в начале 1940х годов тубокурарин использовали для расслабления мышц у детей со спастическими формами детского церебрального паралича. Но только в 1959 году появляются первые научные работы, в которых кардиазоловую судорожную терапию пытались сочетать с применением современного деполяризующего миорелаксанта короткого действия - сукцинилхолина (листенона, дитилина) [Judah L.N., Murphree O.D., 1959].

Применение миорелаксантов позволило избежать скелетных травм или значительно снизить их риск при применении кардиазола, но породило новые проблемы: к неприятным ощущениям страха, одышки, сердцебиения, паники и тревоги от введения кардиазола добавлялись ощущения полного паралича, удушья, беспомощности и обездвиженности от применения 
миорелаксанта. В то же время применение средств для общей анестезии, например, барбитуратов, для исключения или амнезирования этих неприятных ощущений сталкивалось с уже упоминавшейся нами проблемой взаимного антагонизма кардиазола и барбитуратов, из-за которого судороги либо не возникали вовсе, либо больной успевал проснуться до их начала и испытать неприятные ощущения: страх, тревогу, панику и одновременно удушье и обездвиженность [Judah L.N., Murphree O.D., 1959].

\section{Отхимически индуцированных судорог} к электросудорожной терапии

В 1936 году известный итальянский психиатр профессор Уго Черлетти, вместе со своим учеником Лючио Бини и немецким коллегой Лотаром Калиновски, посетили Вену, чтобы лично увидеть применение ИКТ М. Закелем [Беккер Р.А., Быков Ю.В., 2016]. Там же им впервые довелось увидеть применение Л. Медуной кардиазоловой судорожной терапии. Уже тогда У. Черлетти был удивлён тем фактом, что Л. Медуне не пришла в голову мысль попытаться применить электрическую стимуляцию головного мозга для того, чтобы вызвать лечебный судорожный припадок, поскольку к этому времени уже было известно, что электрическим током тоже можно вызывать судорожные припадки, не носящие летального характера, у экспериментальных животных. Именно после визита в Австрию у У. Черлетти и родилась идея попытаться заменить метод кардиазоловой судорожной терапии - вызыванием лечебных судорог с помощью стимуляции головного мозга электрическим током [Беккер Р.А., Быков Ю.В., 2016].

Основанием для этой идеи У. Черлетти послужило наблюдение о том, что, как мы уже упоминали ранее, больные, подвергавшиеся воздействию кардиазоловой судорожной терапии, очень боялись этого метода лечения и предпринимали всяческие меры для того, чтобы их этим методом больше не лечили - от попыток убежать или спрятаться в шкафу или под кроватью, до агрессии к персоналу и даже суицидов [Fabing H.D., 1942; Беккер Р.А., Быков Ю.В., 2016]. В то же время наблюдение У. Черлетти за тем, как на мясокомбинате, куда на экскурсию его пригласил владелец предприятия - отец невесты его ученика Л. Бини, животных оглушают электрическим током перед забоем, и это не вызывает у животного никакого страха, а приводит к почти мгновенной потере сознания и нередко к возникновению судорог, а также его собственные наблюдения (как до, так и после эпизода на мясокомбинате) за экспериментальными животными, подвергавшимися воздействию электрического тока для вызывания су- 
дорог, навели его на мысль, что, возможно, вызывание лечебных судорог при помощи электрического тока окажется более безопасным, менее болезненным для больного и ассоциирующимся с меньшим страхом и ужасом, методом лечения [Беккер Р.А., Быков Ю.В., 2016].

Уже через несколько лет методика ЭСТ, зародившаяся в Риме, в Италии, благодаря У. Черлетти и Л. Бини, стала доминирующей методикой судорожной терапии. Она постепенно распространилась по всему миру и постепенно вытеснила собой кардиазоловую и триазоловую судорожную терапию, так же, как раньше кардиазол и триазол вытеснили применение камфоры [Gazdag G. et al, 2009].

\section{Сравнительная эффективность химически индуцированных судорог и ЭСТ}

Доказано, что клиническая эффективность химически индуцированных судорог, по статистике, сопоставима с клинической эффективностью ЭСТ [Fink M., 2014]. В то же время нередко отмечался лечебный эффект от применения химической (кардиазоловой или триазоловой) судорожной терапии, при документированной ранее у этого же больного неэффективности применения ЭСТ (резистентности к ней). Возможно, это связано с тем, что при применении химических судорожных агентов продолжительность судорог в среднем больше, а нарушения памяти в среднем гораздо менее выражены, чем при применении ЭСТ, или с тем фактом, что для кардиазоловой судорожной терапии тогдашние руководства рекомендовали более длительный курс (большее количество сеансов), чем для ЭСТ [Fink M., 2014].

Анализируя имеющиеся данные, Макс Финк в 2014 году сделал вывод, что ЭСТ со временем вытеснила химически индуцированные лечебные судороги (кардиазоловые, триазоловые и позднее флюротиловые) только изза большего технического удобства использования ЭСТ, а не вследствие большей её эффективности, и даже не вследствие большей безопасности ЭСТ по сравнению с химически индуцированными судорогами. При применении одинаково модифицированных методик - с общей анестезией и с применением миорелаксантов, премедикацией и ИВЛ - безопасность обоих методов практически одинаково высока. А при применении оригинальных немодифицированных методик - безопасность обоих методов практически одинаково низка, в частности, в отношении таких осложнений, как мышечно-скелетные травмы или длительное апноэ. Как мы знаем сегодня, для эффективности судорожной терапии значение имеет степень вовлечения структур головного мозга в судорожную активность (степень 
генерализации судорожного припадка), длительность и качество припадка, а не сам по себе метод вызывания судорог [Fink M., 2014].

Более того, химически индуцированные судорожные припадки имеют определённые потенциальные терапевтические преимущества перед ЭСТ. А именно, химический метод вызывания лечебных судорог позволяет избежать прямого воздействия электрического тока на головной мозг. Это позволяет обеспечить, при той же общей эффективности судорожной терапии, потенциально меньшее воздействие на память и когнитивные функции больных [Fink M., 2014].

В одном исследовании от 1943 года сравнивали 100 пациентов с шизофренией, которые получали ЭСТ, с такой же группой из 100 пациентов, получавших кардиазоловую (метразоловую) судорожную терапию. Авторы сделали вывод, что применение ЭСТ удобнее, безопаснее и эффективнее кардиазоловой (метразоловой) судорожной терапии, так как больные испытывают меньшее возбуждение, страх и тревогу перед сеансом, меньше боятся ЭСТ по сравнению с кардиазолом, реже отказываются от продолжения терапии. Кроме того, при применении ЭСТ не возникало необходимости в многократных инъекциях раздражающего стенки вен кардиазола, и соответственно не было риска развития флебитов, тромбозов и склерозирования периферических вен. Стоит, однако, отметить, что как ЭСТ, так и кардиазол применялись этими авторами по немодифицированной методике, то есть без применения премедикации, общей анестезии и введения миорелаксантов (что обязательно потребовало бы пункции вен, независимо от способа вызывания судорог) [Reznikoff L., 1943].

\section{Процесс забвения}

Ещё в середине и конце 1950-х годов кардиазоловая или триазоловая судорожная терапия, наряду с ЭСТ, упоминалась в научной литературе и рекомендовалась к использованию, особенно в случаях, резистентных к первым доступным тогда антипсихотикам - АП (хлорпромазину) или антидепрессантам - АД (ипрониазиду, имипрамину). Так, датированная серединой 1950-х годов статья в авторитетном британском журнале Тhe Lancet рекомендовала кардиазоловую судорожную терапию к использованию у пациентов с шизофренией, резистентных к применению хлорпромазина (Ларгактила). Однако вскоре ЭСТ и применение первых АП и АД полностью вытеснили кардиазоловую или триазоловую судорожную терапию. Она была отнесена к истории медицины.

Несмотря на то, что после изобретения в 1938 году У. Черлетти и Л. Бини методики ЭСТ использование кардиазоловой или триазоловой 
судорожной терапии стало быстро сокращаться, по крайней мере в первые 20 лет применение ЭСТ не вытеснило полностью кардиазоловую или триазоловую судорожную терапию. Во многих центрах обе процедуры продолжали практиковаться до конца 1950-х годов, нередко в комбинированном варианте (то есть больной получал сеансы и той, и другой терапии) [Berrios G.E., 1997]. Некоторые психоаналитически ориентированные авторы даже считали, что кардиазол потенциально эффективнее ЭСТ именно вследствие того, что от момента введения кардиазола до момента возникновения судорог больной испытывает сильный страх и тревогу. Они считали, что этот страх и тревога могут привести к некоему «очищению» и переосмыслению больным своего жизненного опыта.

Уже после того, как кардиазол вышел из употребления в качестве метода индукции судорог, он продолжал применяться в малых дозах для увеличения продолжительности судорожных припадков при ЭСТ, для снижения судорожного порога и повышения эффективности ЭСТ. Так, ещё в 1990 году патриарх ЭСТ Макс Финк описал такое применение кардиазола [Fink М., 1990]. Аналогичное описание методики потенцирования ЭСТ предварительным введением метразола (кардиазола) сделано в 1989 году на родине изобретателя метода кардиазоловой судорожной терапии, в Венгрии [Arato et al, 1989]. В настоящее время в таких целях обычно используют кофеин или эуфиллин, никетамид (кордиамин), так как они более доступны [Нельсон А.И., 2005; Быков Ю.В., 2013; Быков Ю.В. с соавт, 2013].

Несмотря на то, что методика кардиазоловой судорожной терапии была практически полностью вытеснена применением ЭСТ и ПФТ после конца 1950-х годов, сама по себе идея индукции лечебных судорог введением химических веществ продолжала иметь своих последователей. Так, на этом же принципе основывалась флуротиловая судорожная терапия - судорожная терапия с помощью ингаляции анестетика флуротила, который, наряду с вызыванием общей анестезии (потери сознания), резко снижает судорожный порог и вызывает судороги. Как оказалось, флуротиловая судорожная терапия была более безопасной с точки зрения вызывания скелетных травм, чем немодифицированная ЭСТ и чем кардиазоловая судорожная терапия, и в ряде случаев оказывалась эффективной при неэффективности ЭСТ. Она применялась и упоминалась в руководствах в качестве альтернативы ЭСТ вплоть до 1960-1970-х годов [Беккер Р.А., Быков Ю.В., 2014]. К сожалению, из-за некоторых проблем, связанных с недостаточно эффективной в то время вентиляцией и опасениями персонала в связи с воздействием флуротила на них, эта методика также отмерла. Однако сама по себе идея химической индукции судо- 
рог при помощи более безопасных терапевтических агентов продолжает оставаться привлекательной и сегодня [Беккер Р.А., Быков Ю.В., 2014].

\section{Заключение}

Как видно из приведённых нами данных литературы, изобретённые Ласло Медуной химически индуцированные (камфорные, а позднее кардиазоловые или триазоловые) судороги были важной исторической вехой на пути к изобретению Уго Черлетти и Лючио Бини методики ЭСТ, а также важной вехой на пути к преодолению существовавшего до начала $\mathrm{XX}$ века терапевтического нигилизма в отношении перспектив лечения психических заболеваний вообще. В свою очередь, преодоление терапевтического нигилизма в отношении возможностей лечения психических заболеваний создало благоприятную атмосферу для дальнейших исследований в этом направлении и для зарождения психофармакотерапии.

Кроме того, как показывает опыт изучения флуротиловой судорожной терапии, идея химической индукции лечебных судорог с помощью более безопасных веществ не потеряла привлекательности и по сей день.

В этом году исполняется 80 лет со дня изобретения методики ЭСТ. Но, несмотря на свой почтенный возраст, ЭСТ и по сей день остаётся непревзойдённым абсолютным чемпионом эффективности при депрессиях. В нерезистентной популяции депрессивных больных её response rate при биполярном наложении электродов и дозе тока около 2,5 судорожного порога превышает $80 \%$, а при дозе тока около 3,5 судорожного порога приближается к 90\% (но с увеличением когнитивных побочных эффектов). У резистентных к АД больных с депрессиями ЭСТ даёт терапевтический эффект в 1/3-2/3 случаев, в зависимости от того, как определять резистентность. Ни один АД до настоящего времени не оказался способен побить этот рекорд эффективности.

Авторы выражают благодарность А.И. Нельсону за критические замечания по ходу подготовки публикации.

\section{Список литературы}

1. Беккер Р.А., Быков Ю.В. Индоклон (флуротил) - историческая альтернатива электросудорожной терапии. Ретроспективный клинический анализ // Дневник психиатра. 2016;01:3-5.

2. Беккер Р.А., Быков Ю.В. История психиатрии: Юлиус Вагнер-Яурегг: две стороны нобелевской награды // Дневник психиатра. 2016; 04: 22-24. 
3. Беккер Р.А., Быков Ю.В. Профессор Уго Черлетти - отец современной электросудорожной терапии // Дневник психиатра. 2016;03:19-20.

4. Быков Ю.В., Беккер Р.А., Резников М.К. Депрессии и резистентность. Практическое руководство для врачей. М.: РИОР: ИНФРА-М., 2013. 374 с.

5. Быков Ю.В., Беккер Р.А. Ласло Медуна - родоначальник судорожной терапии в психиатрии (к 130-летию со дня рождения) // Дневник психиатра. 2016; 02: 26-28.

6. Быков Ю.В. К вопросу об истории применения длительного наркоза в психиатрии. Опубликовано на веб-сайте Российский психореаниматологический pecypc. https://psychoreanimatology.org/.

7. Быков Ю.В. Манфред Закель - основоположник инсулинокоматозной терапии // Дневник психиатра. 2014;04:16-17.

8. Быков Ю.В. Электросудорожная терапия в практике анестезиолога. Научно-практическое пособие. М.: РИОР, Инфра-М, 2013.

9. Нельсон А.И. Электросудорожная терапия в психиатрии, наркологии и неврологии. М: БИНОМ. Лаборатория знаний, 2005. 368 с.

10. Baran B, Bitter I, Ungvari GS et al. The beginning of modern psychiatric treatment in Europe: lessons from an early account of convulsive therapy // Eur Arch Psychiatry Clin Neurosci 2008;258:434-440.

11. Baran B, Bitter I, Ungvari GS, Gazdag G. The birth of convulsive therapy revisited: a reappraisal of LászlóMeduna's first cohort of patients // J Affect Disord. 2012;136(3):1179-1182.

12. Bennett AE. Metrazol convulsive shock therapy in depressive psychoses // Am J Med Sci 1939; 98:695-701.

13. Berrios GE. The scientific origins of electroconvulsive therapy: a conceptual history // Hist Psychiatry. 1997;8(29 pt 1):105-119.

14. Cook LC.Cardiazol Convulsion Therapy in Schizophrenia // Proc R Soc Med. 1938;31(6): 567-577.

15. Cooper K, Fink M. The chemical induction of seizures in psychiatric therapy: were flurothyl (indoklon) and pentylenetetrazol (metrazol) abandoned prematurely? // J Clin Psychopharmacol. 2014;34(5):602-607.

16. Dhunjibhoy JE. Treatment of Schizophrenia by Inducing Epileptiform Shocks by the Drug Cardiazol: An Experimental Study of 42 Cases // Ind Med Gaz. 1938;73(6):321-326.

17. Fabing HD. Induction of Metrazol Convulsions with the Patient under Nitrous Oxide Anesthesia // Neur Psych. 1942;47(2):223-233.

18. Fink M. Induced seizures as psychiatric therapy: Ladislas Meduna's contribution in modern neuroscience // J ECT. 2004;20:133-136. 
19. Fink M. Meduna and the origins of convulsive therapy // Am J Psychiatry. 1984;141(9):1034-41.

20. Fink M. The seizure, not electricity, is essential in convulsive therapy: the flurothyl experience // J ECT. 2014;30(2):91-93.

21. Fink M. The Use of Metrazol in the Treatment of Patients with Mental Diseases // Convuls Ther. 1990;6(4):287-298.

22. Gazdag G, Bitter I, Ungvari GS et al. LászlóMeduna's pilot studies with camphor inductions of seizures: the first 11 patients // J ECT. 2009; 25: 3-11.

23. Gazdag G, Bitter I, Ungvari GS, Baran B. Convulsive therapy turns 75 // Br J Psychiatry. 2009;194(5):387-388.

24. Hayman M, Brody MW. Metrazol therapy in schizophrenia report of a fatal case with autopsy // JAMA. 1939;112(4):310-311.

25. Judah LN, Murphree OD. Metrazol convulsive therapy modified by succinylcholine // J Nerv Ment Dis. 1959;129:198-200.

26. Kennedy A. A critical review: the treatment of mental disorders by induced convulsions. 1940;3(1):49-82.

27. Mankad MV et al. Clinical Manual of Electroconvulsive Therapy. American Psychiatric Publishing. Arlington, VA, 2010.

28. McCrae N. 'A violent thunderstorm': Cardiazol treatment in British mental hospitals // Hist Psychiatry. 2006;17(65 Pt 1):67-90.

29. Meduna L. Die Konvulsionstherapie der Schizophrenie [Convulsive Therapy in Schizophrenia]. Carl Marhold,1937.

30. Meduna L. Versucheüber die biologischeBeeinflussung des Ablaufes der Schizophrenie [Attempt at biological influencing of the course of schizophrenia] // Z Neur Psych 1935; 152: 235-262.

31. Meduna LJ. 'Die Konvulsionstherapie der Schizophrenie' (Halle: Carl Marhold), 1937.

32. Meduna LJ. 'Dysharmonism in in psychosis and its correction by shock' // Journal of Nervous and Mental Disease. 1943. xcviii, 5-13.

33. Meduna LJ. 'General discussion of the cardiazol therapy'// American Journal of Psychiatry, 1938. xciv (Suppl.), 40-50.

34. Meduna LJ. The convulsive treatment // J Clin Exp Psychopathol Quart Rev Psychiat Neurol 1954; 15: 219-233.

35. Muller G. [Seizures in schizophrenic psychoses]. Allg Z Psychiatr 1930; 83: 242-261.

36. Read CF. Consequences of metrazol shock therapy. 1940; 97(3):667-676.

37. Redlich FC. Metrazol shock treatment // Pharmacological and Biochemical Studies. 1939; 1(96):193-04. 
38. Reznikoff L. Comparison of metrazol convulsive therapy with electric shock in treatment of schizophrenia // Arch Neurol And Psychiat. 1943: 49(4): 587-593.

39. Whitaker R. Mad in America: Bad Science, Bad Medicine, and the Enduring Mistreatment of the Mentally Ill (2002), pp. 91-96.

\section{References}

1. Bekker R.A., Bykov Yu.V. Dnevnik psikhiatra. 2016;01:3-5.

2. Bekker R.A., Bykov Yu.V. Dnevnik psikhiatra. 2016; 04: 22-24.

3. Bekker R.A., Bykov Yu.V. Dnevnik psikhiatra. 2016;03:19-20.

4. Bykov Yu.V., Bekker R.A., Reznikov M.K. Depressii i rezistentnost' [Depression and resistance]. M.: RIOR: INFRA-M., 2013. 374 p.

5. Bykov Yu.V., Bekker R.A. Dnevnik psikhiatra. 2016; 02: 26-28.

6. Bykov Yu.V. K voprosu ob istorii primeneniya dlitel'nogo narkoza v psikhiatrii [On the history of the use of prolonged anesthesia in psychiatry]. https://psychoreanimatology.org/ Dostup k stat'e proveren 16.02.2018.

7. Bykov Yu.V. Dnevnik psikhiatra. 2014;04:16-17.

8. Bykov Yu.V. Elektrosudorozhnaya terapiya v praktike anesteziologa [Electroconvulsive therapy in the practice of an anesthesiologist]. M.: RIOR, Infra-M, 2013.

9. Nel'son A.I. Elektrosudorozhnaya terapiya v psikhiatrii, narkologii $i$ nevrologii [Electroconvulsive therapy in psychiatry, narcology and neurology]. M: BINOM. Laboratoriya znaniy, 2005. 368 p.

1. Baran B, Bitter I, Ungvari GS et al. The beginning of modern psychiatric treatment in Europe: lessons from an early account of convulsive therapy. Eur Arch Psychiatry Clin Neurosci 2008;258:434-440.

2. Baran B, Bitter I, Ungvari GS, Gazdag G. The birth of convulsive therapy revisited: a reappraisal of LászlóMeduna's first cohort of patients. J Affect Disord. 2012;136(3):1179-1182.

3. Bennett AE. Metrazol convulsive shock therapy in depressive psychoses. Am J Med Sci 1939; 98:695-701.

4. Berrios GE. The scientific origins of electroconvulsive therapy: a conceptual history. Hist Psychiatry. 1997;8(29 pt 1):105-119.

5. Cook LC.Cardiazol Convulsion Therapy in Schizophrenia. Proc R Soc Med. 1938;31(6): 567-577.

6. Cooper K, Fink M. The chemical induction of seizures in psychiatric therapy: were flurothyl (indoklon) and pentylenetetrazol (metrazol) abandoned prematurely? J Clin Psychopharmacol. 2014;34(5):602-607.

7. Dhunjibhoy JE. Treatment of Schizophrenia by Inducing Epileptiform Shocks by the Drug Cardiazol: An Experimental Study of 42 Cases. Ind Med Gaz. 1938;73(6):321-326. 
8. Fabing HD. Induction of Metrazol Convulsions with the Patient under Nitrous Oxide Anesthesia. Neur Psych. 1942;47(2):223-233.

9. Fink M. Induced seizures as psychiatric therapy: Ladislas Meduna's contribution in modern neuroscience. $J$ ECT. 2004;20:133-136.

10. Fink M. Meduna and the origins of convulsive therapy. Am J Psychiatry. 1984;141(9):1034-41.

11. Fink M. The seizure, not electricity, is essential in convulsive therapy: the flurothyl experience. $J$ ECT. 2014;30(2):91-93.

12. Fink M. The Use of Metrazol in the Treatment of Patients with Mental Diseases. Convuls Ther. 1990;6(4):287-298.

13. Gazdag G, Bitter I, Ungvari GS et al. LászlóMeduna's pilot studies with camphor inductions of seizures: the first 11 patients. JECT. 2009; 25: 3-11.

14. Gazdag G, Bitter I, Ungvari GS, Baran B. Convulsive therapy turns 75. Br J Psychiatry. 2009;194(5):387-388.

15. Hayman M, Brody MW. Metrazol therapy in schizophrenia report of a fatal case with autopsy JAMA. 1939;112(4):310-311.

16. Judah LN, Murphree OD. Metrazol convulsive therapy modified by succinylcholine. J Nerv Ment Dis. 1959;129:198-200.

17. Kennedy A. A critical review: the treatment of mental disorders by induced convulsions. 1940;3(1):49-82.

18. Mankad MV et al. Clinical Manual of Electroconvulsive Therapy. American Psychiatric Publishing. Arlington, VA, 2010.

19. McCrae N. 'A violent thunderstorm': Cardiazol treatment in British mental hospitals. Hist Psychiatry. 2006;17(65 Pt 1):67-90.

20. Meduna L. Die Konvulsionstherapie der Schizophrenie [Convulsive Therapy in Schizophrenia]. Carl Marhold,1937.

21. Meduna L. Versucheüber die biologischeBeeinflussung des Ablaufes der Schizophrenie [Attempt at biological influencing of the course of schizophrenia]. Z Neur Psych 1935; 152: 235-262.

22. Meduna LJ. 'Die Konvulsionstherapie der Schizophrenie' (Halle: Carl Marhold), 1937.

23. Meduna LJ. 'Dysharmonism in in psychosis and its correction by shock'. Journal of Nervous and Mental Disease. 1943. xcviii, 5-13.

24. Meduna LJ. 'General discussion of the cardiazol therapy'. American Journal of Psychiatry, 1938. xciv (Suppl.), 40-50.

25. Meduna LJ. The convulsive treatment. J Clin Exp Psychopathol Quart Rev Psychiat Neurol 1954; 15: 219-233.

26. Muller G. [Seizures in schizophrenic psychoses]. Allg Z Psychiatr 1930; 83: 242-261. 
27. Read CF. Consequences of metrazol shock therapy. 1940; 97(3):667-676.

28. Redlich FC. Metrazol shock treatment. Pharmacological And Biochemical Studies. 1939; 1(96):193-204.

29. Reznikoff L. Comparison of metrazol convulsive therapy with electric shock in treatment of schizophrenia. Arch Neurol And Psychiat. 1943: 49(4): 587-593.

30. Whitaker R. Mad in America: Bad Science, Bad Medicine, and the Enduring Mistreatment of the Mentally Ill (2002), pp. 91-96.

\section{ДАННЫЕ ОБ АВТОРАХ}

Быков Юрий Витальевич, кандидат медицинских наук, ассистент кафедры анестезиологии, реаниматологии и скорой медицинской помощи

Ставропольский Государственный Медицинский Университет ул. Мира, 310, г. Ставрополь, Ставропольский край, Российская Федераичия

yubykov@gmail.com

Беккер Роман Александрович, магистр в области компьютерных наук, исследователь в области психофармакотерапии Университет им. Давида Бен-Гуриона в Негеве а/я 653, Беер-Шева, 8410501, Израиль rbekker1@gmail.com

\section{DATA ABOUT THE AUTHORS}

Bykov Yuriy Vitalevich, $\mathrm{PhD}$, Assistant of the Department of Anesthesiology, Intensive Care and Emergency Medical Care Stavropol State Medical University 310, Mira Str., Stavropol, Russian Federation yubykov@gmail.com ORCID: 0000-0003-4705-3823

ResearcherID: K-1888-2016

Bekker Roman Aleksandrovich, M.Sc., Researcher

Ben-Gurion University of the Negev

P.O.B. 653, Beer-Sheva, 8410501, Israel

rbekker1@gmail.com

ORCID: 0000-0002-0773-3405

ResearcherID: J-7724-2016 